\title{
Sin registro de donantes de gametos: cerca de treinta años esperando su creación'1.
}

\section{Thirty Years without a Register for gametes donors and still waiting.}

Dra. Yolanda García Ruiz. Profesora Contratada Doctora. Universitat de València. Yolanda.Garcia-Ruiz@uv.es

Resumen. En este estudio planteamos la necesidad de un registro de donantes de gametos y presentamos las claves de por qué no existe aún en España un registro de estas características. Frente a las consecuencias negativas que se pueden derivar de la inexistencia de este tipo de registro, reflexionamos sobre la conveniencia y oportunidad de crear una red de registros de donantes para la medicina del siglo XXI.

\begin{abstract}
In this study it is stated the idea that a register for gametes donors is necessary and we identify the key points explaining why such a register does not exist in Spain. Facing the negative consequences derived from the nonexistence of register for gametes donors, we make a mental construction on the suitability and opportunity of creating a net of national registers for gametes donors.
\end{abstract}

Palabras clave: Registros de donantes de gametos - regulación nacional y comparada - medicina personalizada.

Key words. Registers for gametes donors - national and comparative regulation personalized medicine.

\footnotetext{
1 Trabajo realizado en el marco del Proyecto de investigación DER2013-48284-R sobre “Acceso a la justicia y garantía de los derechos en tiempos de crisis: de los procedimientos tradicionales a los mecanismos alternativos”, dirigido por los Profesores Doctores D. José García Añón y Dña. Ma José Añón Roig y financiado por el Ministerio de Economía y Competitividad. Este trabajo fue finalizado el 30 noviembre de 2015.
} 
García Ruíz, Yolanda: “Sin registro de donantes de gametos: cerca de treinta años esperando su

creación”, IUS ET SCIENTIA, 2015, Vol. 1, No. 1, pp. 41-52.

DOI: http://dx.doi.org/10.12795/IETSCIENTIA.2015.i01.04

\section{INTRODUCCIÓN}

Afirmar que España es una potencia mundial en el ámbito de las técnicas de reproducción humana asistida es una realidad que se explica por la calidad de las clínicas y los tratamientos, el bajo coste de los mismos y la permisividad de la legislación. Todo ello ha permitido que se haya erigido en uno de los principales países de destino del denominado turismo reproductivo ${ }^{2}$.

La primera Ley española que reguló estas prácticas reproductivas fue la Ley 35/1988, de 22 de noviembre, sobre técnicas de reproducción asistida. Ya entonces, en su disposición final tercera, se preveía la creación de un Registro Nacional informatizado de donantes de gametos y preembriones con fines de reproducción humana ${ }^{3}$. La actual Ley 14/2006, de 26 de mayo, sobre técnicas de reproducción humana asistida se refiere también a dicho registro en diversos momentos. Lo hace, desde el mismo preámbulo ${ }^{4}$ y en los artículos 21 y $22^{5}$, para delimitar su función

2 Vid. PENNINGS, G: "Legal harmonization and reproductive tourisme in Europe", Reproductive Health Matters, 2005, 13 (25), 120-128.

${ }^{3}$ La disposición final tercera de la Ley 35/1988, de 22 de noviembre, sobre técnicas de reproducción asistida, establecía:

“El Gobierno, en el plazo de un año, contado a partir de la promulgación de esta Ley, regulará la creación y organización de un Registro Nacional informatizado de donantes de gametos y preembriones con fines de reproducción humana, con las garantías precisas de secreto y en forma de clave:

a) El Registro Nacional consignará, asimismo, cada hijo nacido de los distintos donantes, la identidad de las parejas o mujeres receptoras, y su localización territorial en cada momento, siempre que sea posible.

b) Si en el Registro Nacional o en los centros o servicios en los que se realizan las técnicas de reproducción asistida se tuviere conocimiento de que han fallecido los correspondientes donantes, la muestra donada pasará a disposición de los bancos, que la utilizarán en los términos acordados con aquellos y en base a esta Ley”. Vid. B.O.E. núm. 282, de 24 de noviembre de 1988, pp. 33377 y 33378.

${ }^{4}$ El propio preámbulo de la Ley 14/2006, de 26 de mayo, sobre técnicas de reproducción humana asistida señala: “(...) además del Registro de donantes de gametos y preembriones con fines de reproducción humana, ya previsto en la Ley 35/1988, de 22 de noviembre, se crea el Registro de actividad de los centros de reproducción asistida. En el primero se consignarán los hijos nacidos de cada uno de los donantes, la identidad de las parejas o mujeres receptoras y la localización original de unos y otros en el momento de la donación y de su utilización. Y en el segundo se registrarán los datos sobre tipología de técnicas y procedimientos, tasas de éxito y otras cuestiones que sirvan para 
García Ruíz, Yolanda: “Sin registro de donantes de gametos: cerca de treinta años esperando su creación”, IUS ET SCIENTIA, 2015, Vol. 1, No. 1, pp. 41-52.

\section{DOI: http://dx.doi.org/10.12795/IETSCIENTIA.2015.i01.04}

respecto del registro de actividad de los centros. También alude al registro de donantes al referirse a la confidencialidad de los datos de los donantes de gametos y a la garantía de su anonimato que, como es sabido, se encuentra prevista en el apartado 5 del artículo 5 de la Ley ${ }^{6}$. Y, de nuevo, hace referencia al registro de donantes al regular la Comisión Nacional de Reproducción Humana Asistida, puesto que, según el artículo 20.5, dicha Comisión debe ser informada, anualmente, de los datos recogidos en el registro de donantes y en el registro de actividad de los centros $^{7}$. De hecho, la ausencia de suministro de información por parte de los centros durante un período de un año es considera por la Ley como una infracción grave ${ }^{8}$.

España cuenta, por consiguiente, con una minuciosa regulación que delimita las competencias del registro de donantes, identifica su utilidad y prevé su relevancia. Sin embargo, casi treinta años después de que la Ley de 1988 previera imperativamente su creación y organización, la realidad es que no existe un registro de donantes de gametos. ¿Qué razones se esconden detrás de la pasividad política que ha impedido su creación? ¿Qué consecuencias puede comportar su inexistencia? El presente trabajo pretende dar repuesta a las preguntas precedentes y, asimismo,

informar a los ciudadanos sobre la calidad de cada uno de los centros, que deberán hacerse públicos, al menos, una vez al año”. Vid. B.O.E. núm. 126, de 27 de mayo de 2006, p. 19948.

${ }^{5}$ Ibid., p. 19953.

${ }^{6}$ El apartado 5 del artículo 5 de la Ley Ley 14/2006, de 26 de mayo, sobre técnicas de reproducción humana asistida dispone: “5. La donación será anónima y deberá garantizarse la confidencialidad de los datos de identidad de los donantes por los bancos de gametos, así como, en su caso, por los registros de donantes y de actividad de los centros que se constituyan.

Los hijos nacidos tienen derecho por sí o por sus representantes legales a obtener información general de los donantes que no incluya su identidad. Igual derecho corresponde a las receptoras de los gametos y de los preembriones.

Sólo excepcionalmente, en circunstancias extraordinarias que comporten un peligro cierto para la vida o la salud del hijo o cuando proceda con arreglo a las Leyes procesales penales, podrá revelarse la identidad de los donantes, siempre que dicha revelación sea indispensable para evitar el peligro o para conseguir el fin legal propuesto. Dicha revelación tendrá carácter restringido y no implicará en ningún caso publicidad de la identidad de los donantes”. Ibid., p. 19949.

${ }^{7}$ Ibid., p. 19953.

${ }^{8}$ Vid. Artículo 26.2 b) $4^{\text {a }}$ de la Ley 14/2006, de 26 de mayo, sobre técnicas de reproducción humana asistida. Ibid., p. 19954. 
García Ruíz, Yolanda: “Sin registro de donantes de gametos: cerca de treinta años esperando su creación”, IUS ET SCIENTIA, 2015, Vol. 1, No. 1, pp. 41-52.

\section{DOI: http://dx.doi.org/10.12795/IETSCIENTIA.2015.i01.04}

examinar las opciones más aconsejables en relación a la problemática planteada, teniendo en cuenta que la genética y el origen biológico se van a erigir, con toda probabilidad, en los elementos clave de la medicina del siglo XXI.

\section{2.- ¿PARA QUÉ UN REGISTRO?}

La cuestión relativa a la intervención de donantes de gametos en el ámbito de la reproducción humana asistida se ha abordado de formas muy diferentes en los distintos países que han regulado estas prácticas reproductivas ${ }^{9}$. Algunos Estados han optado por proteger el anonimato de los donantes en sus leyes, tal y como ha hecho España. Otros, por el contrario, han reconocido jurídicamente la posibilidad de que los hijos nacidos de donantes puedan tener conocimiento de su origen biológico. Un ejemplo, en este sentido, es el Reino Unido ${ }^{10}$. Y también existe Estados que, en un intento de armonizar el derecho de los hijos a conocer su filiación biológica y la intimidad de los donantes, se han aventurado a articular un sistema mixto, es decir, un sistema de doble vía que permite a los donantes decidir si quieren permanecer en el anonimato o no como sucede, por ejemplo, en Bélgica ${ }^{11}$.

La opción por un modelo u otro tiene importantes repercusiones jurídicas, además de una clara incidencia en el funcionamiento de las clínicas dedicadas a la reproducción asistida y, asimismo, en el tipo y número de donaciones que se

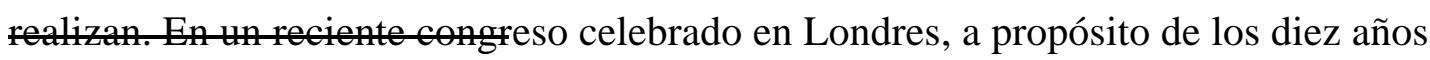

${ }^{9}$ Vid. GARCÍA RUIZ, Y.: Reproducción humana asistida: derecho, conciencia y libertad, Ed. Comares, Granada 2004, pp. 51-187; BLYTH, E. y FRITH, L.: “Donor-conceived people’s access to genetic and biographical history: an analysis of provisions in different jurisdictions permitting disclosure of donor identity”, International Journal of Law, Policy and the Family, 2009, 23, pp. 174191; BÜCHLER, A. y SCHNEIDER KAYASSEH, E.: "Medically Assisted Reproduction in Egypt, Iran, Saudi Arabia and the United Arab Emirates -Sunni and Shia Legal Debates. European Journal of Law Reform, 2014, 16(2), pp. 430-464.

${ }^{10}$ El Reino Unido modificó su legislación para permitir el conocimiento del origen biológico de los nacidos mediante las técnicas de reproducción asistida con intervención de donante a través de 'Human Fertilisation and Embryology Authority (Disclosure of Donor Information) Regulations 2004’. http://www.legislation.gov.uk/uksi/2004/1511/pdfs/uksi_20041511_en.pdf

11 Vid. PENNINGS, G: "Belgian law on medically assisted reproduction and the disposition of supernumerary embryos and gamotes”, European Journal of Health Law, 2008, 14 (3), pp. 251-260. 
de la aprobación de la Ley inglesa que permitió conocer el origen biológico de los hijos nacidos con intervención de donante, alguno de los participantes resaltó el cambio que se había producido en el prototipo de donante que acudía a las clínicas tras permitir conocer a los donantes. Según dichas fuentes, se había pasado del “donante joven que acudía a la clínica para obtener dinero para unas cervezas” a la donación de hombres jóvenes con familias que realizaban la donación por motivos puramente altruistas ${ }^{12}$.

La razón por la cual se modificó la legislación en el Reino Unido a favor del reconocimiento del derecho de los hijos a conocer su origen biológico se halla en el anhelo de los interesados por tener información sobre su pertenencia a una determinada 'familia biológica'. Especialmente relevante, en este sentido, fue el caso de Joanna Rose que contribuyó, de manera decisiva, a la modificación de la legislación británica ${ }^{13}$. La demanda se presentó, en su día, contra la Secretaría de Estado de Salud por dos personas nacidas de donante -Joanna Rose, una mujer que ya era adulta, y por un menor que estaba representado por su madre-. La Corte reconoció la existencia del derecho a conocer su origen biológico y, en su resolución, tuvo muy presente la jurisprudencia del Tribunal Europeo de Derechos Humanos (TEDH) sobre el derecho a la vida privada y familiar. Según la doctrina del citado tribunal europeo, el derecho a la vida privada y familiar comprende, entre otros, el derecho a conocer los detalles sobre la propia identidad y el derecho a obtener información acerca de los padres biológicos ${ }^{14}$.

Además de dichos derechos, tener información sobre el origen biológico es relevante porque la herencia genética puede afectar a la salud. La propia Joanna Rose ha indicado recientemente, a propósito de los diez años de la aprobación de la Ley

\footnotetext{
12 Vid. “Debating donor conception 10 years after the removal of anonymity", BioNews, 9 de noviembre de 2015. http://www.bionews.org.uk/page_583995.asp

${ }^{13}$ Vid. Rose \& Anor v Secretary of State for Health Human Fertilisation and Embryology Authority [2002] EWHC 1593 (Admin) (26 July 2002) England and Wales High Court ((Administrative Court) Decisions, http://www.bailii.org/ew/cases/EWHC/Admin/2002/1593.html

${ }^{14}$ Vid. Al respecto, caso Gaskin v. the United Kingdom, 7 de julio de 1989, Series A no. 160.
} 
británica que permitió conocer a los donantes de gametos, que: “una mala e incompleta historia médica mata a la gente»15.

No es posible, ciertamente, desconocer que la medicina se decanta cada día más por tener en cuenta factores genéticos en el estudio del posible desarrollo de determinadas enfermedades y que algunos tratamientos requieren de donantes compatibles con el paciente que, normalmente, se buscan y se hallan entre los miembros de una misma familia 'biológica'. Por ello, la Ley 14/2006, de 26 de mayo, sobre técnicas de reproducción humana asistida, pese a reconocer y proteger el anonimato de los donantes, en su artículo 5.5 dispone que:

“(...) en circunstancias extraordinarias que comporten un peligro cierto para la vida o la salud del hijo o cuando proceda con arreglo a las Leyes procesales penales, podrá revelarse la identidad de los donantes, siempre que dicha revelación sea indispensable para evitar el peligro o para conseguir el fin legal propuesto.

Dicha revelación tendrá carácter restringido y no implicará en ningún caso publicidad de la identidad de los donantes”.

En consecuencia, ante un caso en el que la salud se encuentre en riesgo, la Ley española prevé la posibilidad de revelar la identidad del donante con ciertas garantías y a modo de excepción. La cuestión que se suscita, sin embargo, es dónde obtener dicha información que puede resultar vital. Evidentemente, la falta de un registro de donantes deja en manos de las clínicas la posibilidad de recabar información sobre el donante. Y, pese a su buen hacer, el mantenimiento de una serie de datos sobre los donantes podría no estar fácilmente disponible, por múltiples razones, ante una posible situación de urgencia.

\section{3.- ¿POR QUÉ NO EXISTE UN REGISTRO EN ESPAÑA?}

La razón por la cual no se ha creado un registro de donantes de gametos en España, pese a estar previsto desde la primera Ley que reguló la reproducción asistida en 1988, responde a razones de índole política y de interés económico.

${ }^{15}$ Vid. "Debating donor conception 10 years after the removal of anonymity”, BioNews, 9 de noviembre de 2015. http://www.bionews.org.uk/page_583995.asp 
Como se ha señalado, España es uno de los destinos preferentes del denominado ‘turismo reproductivo’ y, probablemente, entre las múltiples razones que explican dicha realidad, podría estar la protección del anonimato de los donantes que dificulta que los hijos conozcan su identidad. Si a dicho anonimato se suma la inexistencia de un registro de donantes, las posibilidades de obtener información sobre el origen biológico de los hijos se reducen considerablemente y esta opción puede ser querida por los progenitores en algunos casos.

Es evidente que las técnicas de reproducción asistida han modificado la regulación tradicional en materia de familia. Conceptos jurídicos clásicos como la maternidad y la paternidad se han visto afectados. La paternidad biológica y la paternidad legal se han desligado, como sucede en los supuestos de adopción, y, aunque dicha desvinculación no ha supuesto una novedad jurídica, la cuestión relativa al anonimato de los donantes sí ha introducido un nuevo factor que puede propiciar la aparición de conflictos jurídicos. Algunos Estados, como España, al mantener la identidad de los donantes en el anonimato, optan por un modelo que fomenta la denominada cultura del secreto $^{16}$, buscada por quienes no quieren afrontar en su ámbito familiar o ante los propios hijos el modo en el que se produjo su concepción.

Otra razón relevante por la cual se ha mantenido el anonimato de los donantes en la legislación española y que puede haber influido en la inexistencia de un registro de donantes de gametos es el temor de las clínicas a que se reduzcan las donaciones y a que exista un mayor control respecto al uso de los gametos. Indudablemente, la existencia de un registro de donantes propiciaría un mayor control sobre el número de donaciones que puede realizar un mismo donante en diferentes clínicas y, asimismo, sobre el uso que hacen las clínicas de los gametos de un mismo donante. A este respecto, conviene recordar que, según dispone el artículo 5.7 de la Ley 14/2006, de 26 de mayo, sobre técnicas de reproducción humana asistida, el número máximo autorizado de hijos nacidos en España con gametos de un mismo donante no dehe ser superior a seis. Pero ¿qué sucede con los nacidos en

${ }^{16}$ Vid. PETERSEN, K.: "The right of donor-conceived children to know the identity of their donor", Globalization and health, Ed. Springerlink, Netherlands 2006, pp. 151-167. 
otros países que hayan sido concebidos en España? ¿Cabría utilizar los gametos de un mismo donante para concebir seis hijos nacidos en España y seis nacidos en Francia y seis en Italia, etc.? Evidentemente, la existencia de un registro de donantes evitaría posibles abusos o interpretaciones económicamente interesadas de la legislación.

\section{4. ¿QUÉ CONSECUENCIAS SE PUEDEN DERIVAR DE LA INEXISTENCIA DEL REGISTRO?}

Algunas de las consecuencias más graves que se pueden derivar de la falta de un registro de donantes de gametos han sido ya enunciadas y revelan una importante ausencia de control. No es difícil imaginar que algunas jóvenes, con escasos recursos económicos, se dediquen a recorrer clínicas donando óvulos, dadas las cantidades que se pagan a título de compensación por las molestias ${ }^{17}$. La posible incidencia de los tratamientos reiterados en su salud es un tema a considerar; y también lo es la obtención de gametos de un mismo donante por parte de diferentes clínicas que, difícilmente sabrán si el donante ha donado previamente o no, dada la inexistencia de un registro. Esta situación hace prácticamente imposible controlar el número de hijos que nacen actualmente de un mismo donante en España y ello puede provocar problemas de consanguinidad en el futuro. Además, como se ha señalado anteriormente, al no existir un registro se carece de un auténtico control sobre los donantes y ello pone en riesgo datos médicos y de identificación que pueden ser vitales para la salud de los hijos en el futuro.

Por otro lado, es importante señalar que, la ausencia de un registro de donantes, implica que España está incumpliendo lo dispuesto en la Directiva 2006/17/CE de la Comisión, de 8 de febrero de 2006, por la que se aplica la Directiva 2004/23/CE del Parlamento Europeo y del Consejo en lo relativo a determinados requisitos técnicos para la donación, la obtención y la evaluación de

\footnotetext{
${ }^{17}$ La cantidad suele ser en torno a los mil euros.
} 
García Ruíz, Yolanda: “Sin registro de donantes de gametos: cerca de treinta años esperando su creación”, IUS ET SCIENTIA, 2015, Vol. 1, No. 1, pp. 41-52.

\section{DOI: http://dx.doi.org/10.12795/IETSCIENTIA.2015.i01.04}

células y tejidos humanos. En concreto, la inexistencia de un Registro de donantes conlleva el incumplimiento de la citada Directiva respecto de la "trazabilidad", es decir, respecto de la capacidad de localizar e identificar una célula o un tejido en cualquiera de las fases desde su obtención hasta su destino. Y, al respecto, es importante destacar que la trazabilidad también conlleva la capacidad de identificar al donante.

\section{UNA RED DE REGISTROS DE DONANTES PARA LA MEDICINA DEL SIGLO XXI}

A tenor de lo señalado, empieza a ser urgente diseñar una Red de Registros de Donantes que comprenda distintos niveles: Registros Autonómicos que viertan sus datos en un Registro Nacional que, a su vez, estuviera conectado con un futuro Registro europeo ${ }^{18}$. La creación de una Red de Registros de Donantes supondría un primer paso para cumplir con las exigencias europeas de trazabilidad respecto de la identificación de los donantes en los procesos reproductivos. Además, facilitaría el control del número de donaciones que realiza un mismo donante, con el objeto de evitar problemas de consanguinidad y crearía las bases necesarias para poder enfrentar, llegado el caso, una reforma legislativa que posibilitara conocer el origen biológico a los hijos de donante. Al respecto, conviene no olvidar que en otros países, como el Reino Unido, han sido los propios interesados los que, utilizando la vía judicial, han forzado cambios legislativos favorables al reconocimiento del derecho a conocer su origen biológico ${ }^{19}$.

18 Vid. GARCÍA RUIZ, Y.: El origen biológico en la reproducción asistida: nuevas tendencias normativas para una era global, Centro de Estudios Andaluces, Policy Paper, nº 9, mayo 2010, p. 13.

${ }^{19}$ Por lo que respecta a España, en relación con el derecho a conocer el origen biológico, cabe señalar su reconocimiento explícito en la legislación en materia de adopción. Ello supone un precedente normativo que evidencia una clara discriminación respecto de los hijos de donantes en España. En concreto, dicho derecho se ha reconocido en el artículo 12 de la Ley 54/2007, de 28 de diciembre, de Adopción internacional, el cual dispone que: "Las personas adoptadas, alcanzada la mayoría de edad o durante su minoría de edad representadas por sus padres, tendrán derecho a conocer los datos que sobre sus orígenes obren en poder de las Entidades Públicas españolas, sin perjuicio de las limitaciones que pudieran derivarse de la legislación de los países de que provengan los menores. Este derecho se hará efectivo con el asesoramiento, la ayuda y mediación de los servicios especializados de la Entidad Pública de Protección de Menores u organizaciones autorizadas para tal fin. 
Los registros de donantes de gametos autonómicos podrían funcionar también como registros de hermanos de donantes, a semejanza del creado a comienzos del año 2000 en Estados Unidos (Donor Sibling Registry) ${ }^{20}$. Los hijos nacidos de donantes, además de recurrir a los tribunales para que les reconozcan el derecho a conocer su origen biológico, han hecho uso también de las nuevas tecnologías de la información que les han permitido crear espacios de encuentro entre los miembros de una misma familia biológica, es decir, entre los hijos y los donantes y también entre los hermanos nacidos de un mismo donante.

La primera iniciativa en este sentido surgió, según se ha indicado, en Estados Unidos y funciona, fundamentalmente, como un Registro privado de hermanos de donantes. Ante vacío legal existente sobre estos temas en Estados Unidos, dicho registro facilita información sobre los donantes y sobre los posibles hermanos, nacidos de un mismo donante, erigiéndose, en definitiva, en un auténtico canal de información y comunicación entre los miembros de una misma familia biológica.

Con posterioridad, otros países han creado también registros similares que permiten entrar en contacto a hermanos nacidos de un mismo donante. Un caso a destacar es el registro existente en el Reino Unido puesto que, además de facilitar información y ayuda a los hijos de donantes, asesora y ayuda a los padres cuando los hijos deciden buscar a los donantes y a sus hermanos biológicos ${ }^{21}$.

Las experiencias personales y las relaciones que están surgiendo entre las personas de una misma familia biológica, que entran en contacto a través de estos registros, constituyen un elemento de gran relevancia a la hora de determinar la adopción de políticas legislativas en el futuro. En este sentido, ya existe un

Las Entidades Públicas competentes asegurarán la conservación de la información de que dispongan relativa a los orígenes del niño, en particular la información respecto a la identidad de sus padres, así como la historia médica del niño y de su familia.

Las Entidades colaboradoras que hubieran intermediado en la adopción deberán informar a las Entidades Públicas de los datos de los que dispongan sobre los orígenes del menor”. Vid. B.O.E., núm 312, de 29 de diciembre de 2007, p. 53681.

\footnotetext{
${ }^{20}$ http://www.donor-siblingregistry.com

${ }^{21}$ http://www.hfea.gov.uk/donor-sibling-link.html
} 
interesante estudio, desarrollado por un equipo del Center for Family Research de la Universidad de Cambridge, dirigido por la prestigiosa psicóloga británica Susan Golombok $^{22}$, en el cual, a través de un cuestionario online, se han examinado las experiencias de algunas de las personas registradas en el Donor Sibling Registry de Estados Unidos. Los resultados de dicha investigación muestran una prevalencia significativa de experiencias positivas tras los contactos mantenidos entre los hermanos nacidos de un mismo donante y, asimismo, entre los hijos y los donantes.

\section{REFLEXIÓN FINAL}

Ha llegado el momento de acometer con valentía la creación del registro de donantes de gametos previsto desde 1988. Razones éticas, jurídicas y médicas lo están reclamando desde hace demasiado tiempo. No es posible seguir funcionando bajo el dictado de los intereses económicos. España puede continuar siendo líder y destino preferente de quienes buscan calidad y buen hacer en el marco de la reproducción asistida sin prevalecerse de las aparentes ventajas que se derivan de la inexistencia del registro de donantes. El mandato europeo es claro y no deja lugar a dudas: es necesario garantizar la trazabilidad de cualquier célula o tejido humano y seguir ignorando esta exigencia puede tener consecuencias importantes que pongan en cuestión la buena práctica desarrollada en las clínicas.

El reto ha de estar en el modelo de registro que se quiera establecer. En este sentido, existen ejemplos que han marcado un interesante camino. Facilitar el contacto entre los miembros de una misma familia biológica a través de un registro de donantes que pudiera actuar también como registro de hermanos de donante, aun cuando únicamente fuera a efectos médicos, parece una exigencia que convendría considerar dada la relevancia de la genética en la medicina del siglo XXI.

El negocio reproductivo debe dar paso al servicio en materia de reproducción asistida y, de este modo, construir nuevas fórmulas que continúen dando prestigio a

${ }^{22}$ Vid. GOLOMBOK, S.: “Anonymity -or not- in the Donation of Gametes and Embryos”, Regulating Autonomy. Sex, reproduction and Family, Ed. Shelley Day Sclater, Fatemeh Ebtehaj, Emily Jackson and Martin Richards, 2009, pp. 223-238. 
los tratamientos desarrollados en España. Los excelentes profesionales españoles y la calidad de los centros no deben quedar ensombrecidos por actitudes que revelan intereses económicos alejados de la buena práctica y la ética médica. En este sentido, impulsar y exigir, desde las propias clínicas, la creación del registro de donantes debería ser una cuestión a acometer con urgencia. 